\title{
Etude de la variabilité d'un agent pathogène, Xanthomonas campestris pv manihotis, par l'analyse factorielle multiple
}

\author{
F Grousson ${ }^{1}$, J Pagès ${ }^{2}$, B Boher ${ }^{3}$ \\ ' DDAF du Nord, cité administrative, BP 505, 59022 Lille Cedex; \\ ${ }^{2}$ ENSAR, chaire de mathématiques, 65, route de Saint-Brieuc, 35042 Rennes Cedex, France; \\ ${ }^{3}$ ORSTOM, laboratoire de pathologie végétale, BP 375, Lomé, Togo
}

(Reçu le 11 septembre 1989; accepté le 7 juillet 1990)

\begin{abstract}
Résumé - Cette étude de la variabilité de Xanthomonas campestris pv manihotis, agent de la bactériose vasculaire du manioc, porte sur 54 souches originaires d'Amérique du Sud, et de 5 pays d'Afrique. Des inoculations sur feuilles et sur tiges de 2 cultivars de manioc permettent de reproduire les différents symptômes observés au champ. L'analyse des résultats des inoculations montre une variabilité importante de l'agressivité. In vitro, les souches de Xanthomonas campestris pv manihotis sont relativement homogènes. Cependant, l'étude de leur croissance sur différents substrats, de la réponse à une gamme d'antibiotiques et de la lysotypie fait apparaître une certaine variabilité. La synthèse de l'ensemble des résultats, par une analyse factorielle multiple, montre l'existence d'un facteur commun aux différents caractères étudiés. Il existe, en particulier, une liaison entre l'agressivité des souches et leur comportement in vitro.
\end{abstract}

manioc / agressivité / lysotypie / antibiotique / analyse factorielle

Summary - Study of variability of a pathogenic agent Xanthomonas campestris pv manihotis, by multiple factorial analysis. This study of the variability of Xanthomonas campestris $p v$ manihotis, agent of bacterial blight of cassava, deals with 54 strains from South America and from 5 African countries. Leaf and stem inoculations on 2 cultivars of cassava allow the reproduction of the different symptoms observed in the field. Analysis of inoculation results allows one to define, according to their pathogenicity, 4 groups of strains. The influence of geographical origin is variable: for certain countries or certain areas it appears clearly, while for others it does not seem to exist. In vitro, strains of Xanthomonas campestris pv manihotis are relatively homogenous. Nevertheless, the study of their growth on various substrates, of the response to several antibiotics and of phage typing shows variability. This one is not connected to the geographical origin. Each characteristic allows one to define a stable partition from the set of strains. The synthesis of all the results by way of Multiple Factorial Analysis shows the existence of a common factor to the different characteristics studied. Specifically, a link exists between strains pathogenicity and their in vitro behaviour. The complete data are shown in tables II, IV and VI. Table VII shows the structure of the data table submitted to Multiple Factorial Analysis which takes into account 4 groups of active variables (1, affect induced by inoculation on 2 cultivars; 2 , phage typing; 3, growth on various substrates; 4, response to several antibiotics) and 3 supplementary groups ( groups 3 and 4 recoded in order to measure the influence of coding - geographical origin). Figure 2 gives a factorial representation of variables; the dual representation of individuals is given in figure 3 . The first factor is correlated to variables of all the groups and points out a structure common to the 4 active groups (this result is confirmed by indicators in table VIII).

cassava / pathogenicity / phage typing / antibiotic / factorial analysis 


\section{INTRODUCTION}

Le manioc est attaqué par différents ravageurs et pathogènes. Parmi eux, Xanthomonas campestris pv manihotis est l'agent de la bactériose vasculaire du manioc, maladie provenant d'Amérique du Sud où elle a été signalée pour la première fois en 1912 par Bondar. En Afrique, cette maladie a d'abord été observée au Nigéria en 1972 (Williams et al, 1973). Actuellement, elle est présente dans au moins 15 pays de ce continent.

Les observations concernant la variabilité de Xanthomonas campestris pv manihotis sont contradictoires. Certains auteurs observent une différence de pouvoir pathogène entre les souches étudiées (Bradbury, 1975, 1977; Maraite et Meyer, 1975; Maraite et al, 1981; Alves et Takatsu, 1984). Cette différence est contestée par d'autres auteurs (Nair et al, 1981; Elango et Lozano, 1981).

In vitro, les résultats varient d'un auteur à l'autre, Robbs et al (1972), Elango et al (1981), Manicom et al (1981) n'observent pas de variabilité. Daniel et al (1981) notent seulement des différences de croissance sur amidon et glycérol. Lozano et Sequeira (1974) classent les 15 souches étudiées en 2 groupes selon leur aptitude à utiliser le saccharose, le cellobiose et le tréhalose comme source de carbone. Maraite et al (1981) observent une différence de croissance sur amidon, glycérol, et une utilisation variable de la dextrine, du maltose, du raffinose, du lactose. Ils notent aussi une sensibilité différente à certains antibiotiques.

II est apparu nécessaire de compléter ces travaux sur la variabilité de la bactérie, d'abord afin de montrer l'existence de celle-ci ou la réfuter, puis d'établir les liens éventuels entre les différents caractères étudiés sur l'échantillon de souches.

De plus, l'existence d'une variabilité de l'agressivité présente 2 conséquences importantes. D'une part, il est alors nécessaire de connaître la répartition géographique des souches en fonction de leur agressivité et d'établir une règlementation des échanges internationaux afin d'éviter l'introduction d'une souche très agressive. D'autre part, il faut alors tenir compte de cette variabilité, dans le cadre d'un programme d'amélioration et de sélection de plants résistants à la bactériose vasculaire du manioc.
C'est un échantillon représentatif des souches de la région qui doit être inoculé lors des tests de résistance. Une certaine variabilité de l'hôte doit aussi être maintenue en évitant la monoculture d'un cultivar et en conservant une collection de variétés.

\section{MATÉRIEL ET MÉTHODES}

Dans ce travail, une collection de 54 souches de Xanthomonas campestris pv manihotis, de différentes origines géographiques, a été constituée (tableau I), pour lesquelles on a étudié, principalement, 4 caractères décrits dans les paragraphes suivants.

\section{Agressivité}

L'agressivité des souches est estimée par les résultats des inoculations faites sur feuilles et sur tiges de 2 cultivars de manioc : M'Pembé et Koussakanandi (tableau II).

Sur feuilles, les inoculations sont effectuées sur des plants de 2 mois, cultivés en pots, en perforant les espaces internervaires des folioles à l'aide d'un emportepièce de $1,7 \mathrm{~mm}$ de diamètre trempé dans une culture bactérienne maintenue $48 \mathrm{~h}$ à $30^{\circ} \mathrm{C}$ sur LPGA (Ride $M, 1963)$. La technique utilisée est celle de Buruchara et Pastor-Corrales (1981) et Endert et Ritchie (1984) mesurant le diamètre des lésions causées par Pseudomonas syringae pv syringae. Après $9 \mathrm{j}$ d'incubation à $30{ }^{\circ} \mathrm{C}, 90 \%$ d'humidité et une photopériode de $12 \mathrm{~h}$, la surface de la lésion causée par la souche est mesurée. Elle est ramenée à une couronne de surface équivalente dont on calcule l'épaisseur notée en $10^{-6} \mathrm{~m}$. Dix répétitions par souche et par cultivar sont effectuées et on calcule la moyenne des 10 mesures. Après vérification des hypothèses de normalité et d'égalité des variances, l'analyse de variance montre une différence significative à $1 \%$ entre les moyennes des mesures effectuées sur les 54 souches (Grousson, 1986).

Sur tiges, l'incubation est effectuée sur des plants de manioc d'un mois. La tige est transpercée, au niveau du deuxième entrenœud, avec une aiguille trempée dans une culture bactérienne maintenue $48 \mathrm{~h}$ à $30^{\circ} \mathrm{C}$ sur LPGA. Après 20 j d'inoculation à $30^{\circ} \mathrm{C}, 90 \%$ d'humidité et une photopériode de $12 \mathrm{~h}$, l'intensité de la maladie est notée selon l'échelle suivante :

0 : cicatrisation; 1 : zone vert olive et/ou exsudats autour du point d'inoculation $<20 \mathrm{~mm}$; 2 : zone vert olive et/ou exsudats autour du point d'inoculation > $20 \mathrm{~mm}$; 3 : au moins une feuille flétrie; 4 : dessèchement de l'apex; 5 : mort du plan.

Six plants par souche et par cultivar sont inoculés. Une moyenne des 6 notes est effectuée. 
Tableau I. Références des souches de Xanthomonas campestris pathovar manihotis de la collection.

\begin{tabular}{|c|c|c|c|}
\hline $\begin{array}{c}\text { Origine } \\
\text { géographique }\end{array}$ & $\begin{array}{l}\text { Numéro } \\
\text { étude }\end{array}$ & $\begin{array}{l}\text { Référence } \\
\text { ORSTOM }\end{array}$ & $\begin{array}{c}\text { Date } \\
\text { d'isolement }\end{array}$ \\
\hline Colombie & $\begin{array}{l}1 \\
2 \\
3 \\
4\end{array}$ & $\begin{array}{l}\text { CIAT } 1060 \\
\text { CIAT } 1061 \\
\text { CIAT } 1120 \\
\text { CIAT } 1111\end{array}$ & $\begin{array}{l}1974 \\
1974 \\
1974 \\
1974\end{array}$ \\
\hline Brésil & $\begin{array}{l}5 \\
6 \\
7\end{array}$ & $\begin{array}{l}\text { IBFF } 112 \\
\text { IBFF } 165 \\
\text { IBFF } 107\end{array}$ & $\begin{array}{l}1973 \\
1976 \\
1973\end{array}$ \\
\hline Pointe Noire & 8 & $693-4$ & 1982 \\
\hline Bouenza & $\begin{array}{r}9 \\
10 \\
11 \\
12\end{array}$ & $\begin{array}{l}152 \\
150 \\
798-c \\
803-c\end{array}$ & $\begin{array}{l}1977 \\
1977 \\
1984 \\
1984\end{array}$ \\
\hline Pool & $\begin{array}{l}13 \\
14 \\
15 \\
16 \\
17\end{array}$ & $\begin{array}{l}837 \\
839 \\
840 \\
841 \\
836\end{array}$ & $\begin{array}{l}1984 \\
1984 \\
1984 \\
1984 \\
1984\end{array}$ \\
\hline Plateaux & $\begin{array}{l}18 \\
19 \\
20 \\
21 \\
22 \\
23 \\
24 \\
25\end{array}$ & $\begin{array}{l}104-2 \\
293-1 \\
298-2 \\
336 \\
386-b \\
589 \\
720-3 \\
721\end{array}$ & $\begin{array}{l}1979 \\
1979 \\
1979 \\
1979 \\
1980 \\
1981 \\
1982 \\
1982\end{array}$ \\
\hline Cuvette & $\begin{array}{l}26 \\
27 \\
28 \\
29 \\
30 \\
31 \\
32 \\
33\end{array}$ & $\begin{array}{l}773-4 \\
770-3 \\
781 \\
775 \\
767 \\
779 \\
780 \\
716-4\end{array}$ & $\begin{array}{l}1983 \\
1983 \\
1983 \\
1983 \\
1983 \\
1983 \\
1983 \\
1982\end{array}$ \\
\hline Bénin & $\begin{array}{l}34 \\
35 \\
36 \\
37 \\
38\end{array}$ & $\begin{array}{l}674-1 \\
677-1 \\
676-1 \\
680-2 \\
675\end{array}$ & $\begin{array}{l}1982 \\
1982 \\
1982 \\
1982 \\
1982\end{array}$ \\
\hline RCA & $\begin{array}{l}39 \\
40 \\
41\end{array}$ & $\begin{array}{l}107-8 \\
113 \\
105-9\end{array}$ & $\begin{array}{l}1977 \\
1977 \\
1977\end{array}$ \\
\hline Nigéria & $\begin{array}{l}42 \\
43\end{array}$ & $\begin{array}{l}206-1 \\
204-1\end{array}$ & $\begin{array}{l}1978 \\
1978\end{array}$ \\
\hline Zaïre & $\begin{array}{l}44 \\
45 \\
46 \\
47 \\
48 \\
49 \\
50 \\
51 \\
52 \\
53 \\
54\end{array}$ & $\begin{array}{l}276-3 \\
278-1 \\
275-2 \\
280-1 \\
274-2 \\
279 \\
312 \\
311 \\
309 \\
310-2 \\
273-3\end{array}$ & $\begin{array}{l}1979 \\
1979 \\
1979 \\
1979 \\
1979 \\
1979 \\
1979 \\
1979 \\
1979 \\
1979 \\
1979\end{array}$ \\
\hline
\end{tabular}

Tableau II. Agressivité des souches de $X c \mathrm{pv}$ manihotis. La mesure sur feuilles est la moyenne de 10 mesures de surface de lésion après inoculation en condition standard. La notation sur tige est la moyenne de six notes d'intensité de la maladie (de 0 à 5) après inoculation en condition standard.

\begin{tabular}{|c|c|c|c|c|}
\hline \multirow[b]{2}{*}{$N^{\circ}$} & Mesures & ur feuilles & Notations & sur tiges \\
\hline & $\begin{array}{c}\text { Cultivar } \\
\text { M'Pembé }^{\prime} \text { Pember }\end{array}$ & $\begin{array}{l}\text { Cultivar } \\
\text { Koussa- } \\
\text { kanandi }\end{array}$ & $\begin{array}{l}\text { Cultivar } \\
\text { M'Pembé }^{\prime} \text { Pet }\end{array}$ & $\begin{array}{l}\text { Cultivar } \\
\text { Koussa- } \\
\text { kanandi }\end{array}$ \\
\hline
\end{tabular}

\begin{tabular}{|c|c|c|c|c|}
\hline 1 & 571 & 121 & 4,00 & 4,00 \\
\hline 2 & 566 & 147 & 4,50 & 4,00 \\
\hline 3 & 530 & 122 & 4,33 & 4,25 \\
\hline 4 & 000 & 000 & 0,00 & 0,50 \\
\hline 5 & 687 & 163 & 3,60 & 4,33 \\
\hline 6 & 161 & 059 & 4,67 & 2,33 \\
\hline 7 & 042 & 033 & 2,50 & 0,50 \\
\hline 8 & 572 & 169 & 4,50 & 3,67 \\
\hline 9 & 062 & 126 & 3,00 & 2,33 \\
\hline 10 & 148 & 040 & 1,50 & 0,50 \\
\hline 11 & 277 & 124 & 1,40 & 1,14 \\
\hline 12 & 535 & 264 & 4,00 & 3,00 \\
\hline 13 & 501 & 335 & 5,00 & 2,67 \\
\hline 14 & 704 & 134 & 5,00 & 2,67 \\
\hline 15 & 661 & 237 & 5,00 & 4,33 \\
\hline 16 & 675 & 304 & 4,20 & 2,67 \\
\hline 17 & 733 & 289 & 3,67 & 1,83 \\
\hline 18 & 160 & 210 & 1,00 & 1,50 \\
\hline 19 & 315 & 168 & 4,33 & 2,00 \\
\hline 20 & 255 & 089 & 1,83 & 2,50 \\
\hline 21 & 515 & 109 & 4,00 & 2,67 \\
\hline 22 & 152 & 030 & 0,67 & 1,67 \\
\hline 23 & 322 & 091 & 3,17 & 3,33 \\
\hline 24 & 688 & 251 & 4,00 & 4,00 \\
\hline 25 & 586 & 128 & 4,67 & 3,33 \\
\hline 26 & 455 & 170 & 3,83 & 4,33 \\
\hline 27 & 694 & 028 & 4,50 & 4,67 \\
\hline 28 & 614 & 122 & 3,83 & 3,00 \\
\hline 29 & 360 & 078 & 4,67 & 4,00 \\
\hline 30 & 430 & 140 & 3,67 & 4,00 \\
\hline 31 & 238 & 033 & 3,00 & 2,50 \\
\hline 32 & 468 & 017 & 4,33 & 3,17 \\
\hline 33 & 381 & 038 & 4,33 & 4,33 \\
\hline 34 & 139 & 097 & 4,50 & 4,17 \\
\hline 35 & 315 & 063 & 4,67 & 3,50 \\
\hline 36 & 200 & 043 & 2,67 & 4,00 \\
\hline 37 & 258 & 032 & 4,33 & 3,50 \\
\hline 38 & 198 & 105 & 4,00 & 3,83 \\
\hline 39 & 082 & 052 & 3,67 & 4,00 \\
\hline 40 & 027 & 025 & 2,17 & 3,00 \\
\hline 41 & 009 & 000 & 0,40 & 1,83 \\
\hline 42 & 015 & 004 & 1,67 & 0,50 \\
\hline 43 & 011 & 016 & 2,33 & 2,83 \\
\hline 44 & 290 & 092 & 3,00 & 4,17 \\
\hline 45 & 367 & 029 & 4,83 & 3,50 \\
\hline 46 & 347 & 011 & 3,60 & 3,67 \\
\hline 47 & 267 & 063 & 2,67 & 3,83 \\
\hline 48 & 251 & 052 & 4,17 & 3,50 \\
\hline 49 & 070 & 003 & 1,33 & 2,17 \\
\hline 50 & 249 & 053 & 4,33 & 2,50 \\
\hline 51 & 382 & 113 & 4,50 & 4,50 \\
\hline 52 & 239 & 096 & 3,33 & 4,67 \\
\hline 53 & 300 & 047 & 4,67 & 3,50 \\
\hline 54 & 313 & 044 & 5,00 & 4,33 \\
\hline
\end{tabular}




\section{Lysotypie}

A partir de feuilles de manioc atteintes de bactériose, de sol et de débris prélevés sous des plants dans différentes régions du Congo, 9 phages ont été isolés.

L'isolement et la multiplication des phages sont effectués dans du bouillon nutritif (extrait de boeuf : 200 $\mathrm{ml}$, chlorure de sodium : $5 \mathrm{~g}$, bactopeptone : $10 \mathrm{~g}$, eau distillée : $800 \mathrm{ml}, \mathrm{pH}=7$ ). La purification et le titrage des suspensions phagiques sont effectués sur nappes bactériennes en double couche de gélose nutritive, selon la technique de Cuppels (1983), à l'aide d'une souche indicatrice (la souche 17). Les boîtes de Pétri sont maintenues à $25^{\circ} \mathrm{C}$, cette température étant plus favorable à la formation de plages de lyse que la température optimale de croissance de la bactérie (environ $30^{\circ} \mathrm{C}$ ). Pour chaque couple (souche, phage), sont préparées 2 nappes bactériennes sur double couche, ce qui constitue 2 répétitions. Sur ces nappes sont déposées des gouttes de $0,01 \mathrm{ml}$ de 10 dilutions des suspensions phagiques. Après $48 \mathrm{~h}$, on compare la dilution de la dernière lyse confluente à la RTD (Routine Test Dilution : plus faible concentration de phages nécessaire pour produire une lyse confluente sur la couche indicatrice). La notation est effectuée ainsi : + : dernière lyse confluente au maximum à une dilution de la RTD, - : dernière lyse confluente à au moins 2 dilutions de la RTD (tableau III).

\section{Croissance sur différents substrats carbonés}

La technique et le milieu utilisés sont ceux de Hayward et Hogkiss (1961). Comme Stanier et al (1966) le conseillent, une concentration de substrats de 0,2\% est incluse dans le milieu. Les solutions de substrats sont ajoutées après autoclavage du milieu et stérilisées par ultrafiltration. Dix-neuf substrats sont inclus chacun dans un milieu de culture. Quarante-huit heures après incubation à $30^{\circ} \mathrm{C}$, on mesure la croissance de chaque souche sur chaque substrat à l'aide d'une échelle de notation allant de 0 à 4 . L'expérience est effectuée 2 fois et compte chaque fois 2 répétitions. Ce premier codage met en évidence un groupe de souches, prépondérant, homogène quant à la croissance sur ces substrats. Pour atténuer le caractère subjectif d'une notation, les notes initiales ont été recodées en référence à ce groupe, appelé $\mathrm{MO}:>$ : la croissance de la souche est plus importante que celle du groupe de référence; < : la croissance de la souche est moins importante que celle du groupe de référence; = : la croissance de la souche est comparable à celle du groupe de référence (tableau IV).

\section{Sensibilité aux antibiotiques}

La sensibilité in vitro des souches en présence de 48 antibiotiques est testée par la méthode des antibiogrammes et notée selon les normes de l'Institut Pas-
Tableau III. Lysotypie des souches de $X c p v$ manihotis.

\begin{tabular}{|c|c|c|c|c|c|c|c|c|c|}
\hline & $D$ & $K$ & $C$ & $P$ & $L$ & $E$ & 1 & $O$ & $G$ \\
\hline 1 & - & + & + & + & + & + & + & - & + \\
\hline 2 & - & - & - & - & - & - & - & - & - \\
\hline 3 & - & + & + & + & + & + & - & - & + \\
\hline 4 & - & - & - & - & - & + & - & - & - \\
\hline 5 & - & - & - & - & - & - & - & - & - \\
\hline 6 & + & + & + & + & + & + & + & - & + \\
\hline 7 & - & - & - & - & - & - & - & - & - \\
\hline 8 & + & + & + & + & + & + & + & - & - \\
\hline 9 & - & + & + & + & + & - & - & - & - \\
\hline 10 & + & + & + & + & + & + & + & - & - \\
\hline 11 & - & - & - & - & - & - & - & - & - \\
\hline 12 & + & + & + & + & + & + & + & - & + \\
\hline 13 & + & + & + & + & + & + & + & + & + \\
\hline 14 & - & + & + & + & + & + & + & + & + \\
\hline 15 & - & + & + & - & + & + & + & + & - \\
\hline 16 & + & + & + & + & + & + & + & + & + \\
\hline 17 & + & + & + & + & + & + & + & + & + \\
\hline 18 & - & - & - & - & - & - & - & - & - \\
\hline 19 & - & + & + & + & + & + & + & + & + \\
\hline 20 & - & - & - & - & - & - & - & - & - \\
\hline 21 & - & - & - & - & + & + & + & + & + \\
\hline 22 & + & + & + & + & - & - & - & - & - \\
\hline 23 & - & - & - & - & - & - & - & - & - \\
\hline 24 & + & + & + & + & + & + & + & + & + \\
\hline 25 & - & + & - & - & + & + & + & + & - \\
\hline 26 & + & + & + & + & + & + & + & + & - \\
\hline 27 & + & + & + & + & + & + & + & + & - \\
\hline 28 & + & + & + & + & + & + & + & + & - \\
\hline 29 & - & + & - & - & + & + & + & + & - \\
\hline 30 & - & - & - & - & - & - & - & - & - \\
\hline 31 & + & + & + & + & + & + & + & + & - \\
\hline 32 & + & + & + & + & + & + & + & + & - \\
\hline 33 & + & + & + & + & + & + & - & + & - \\
\hline 34 & + & + & + & + & + & + & + & + & - \\
\hline 35 & + & + & + & + & + & + & + & + & + \\
\hline 36 & + & + & + & + & + & + & + & + & + \\
\hline 37 & - & + & - & - & + & + & + & + & + \\
\hline 38 & - & + & + & + & + & + & + & + & + \\
\hline 39 & - & + & + & + & + & + & + & + & + \\
\hline 40 & - & + & + & + & + & + & + & + & + \\
\hline 41 & - & - & - & - & - & - & - & - & - \\
\hline 42 & - & - & - & - & + & + & - & + & - \\
\hline 43 & - & + & - & - & + & + & - & + & - \\
\hline 44 & + & + & + & + & + & + & + & + & + \\
\hline 45 & + & + & + & + & + & + & - & + & + \\
\hline 46 & + & + & + & + & + & + & - & + & + \\
\hline 47 & + & + & + & + & + & + & - & + & + \\
\hline 48 & - & + & + & - & + & + & - & + & + \\
\hline 49 & - & + & - & - & + & + & - & - & - \\
\hline 50 & - & - & - & - & - & - & - & - & - \\
\hline 51 & + & + & + & + & + & + & + & - & - \\
\hline 52 & + & + & + & + & + & + & + & - & - \\
\hline 53 & + & + & + & + & + & + & + & - & - \\
\hline 54 & - & + & + & + & + & + & + & - & - \\
\hline
\end{tabular}

La notation de la lysotypie est effectuée en référence à la souche 17, dite souche indicatrice, qui a servi à isoler les phages.

Notation :

- si la souche est moins sensible au phage que la souche indicatrice,

+ si la souche est aussi sensible au phage que la souche indicatrice. 
Tableau IV. Recodage en modalités des variables liées à la croissance sur différents substrats carbonés des souches $X c p v$ manihotis.

La notation est faite en référence à un ensemble, noté $\mathrm{MO}$, de 38 souches absolument identiques quant à la croissance sur ces substrats.

\begin{tabular}{|c|c|c|c|c|c|c|c|c|c|c|c|c|c|c|}
\hline$N^{0}$ & $T$ & $G A$ & $M A$ & $L A$ & $E R$ & $R I$ & $A R$ & $R A$ & $A M$ & $X Y$ & $S A$ & $R H$ & $A E$ & $G L$ \\
\hline 1 & $=$ & $=$ & $=$ & $=$ & $=$ & $=$ & $=$ & $=$ & $>$ & $=$ & $=$ & $=$ & $=$ & $=$ \\
\hline 2 & $=$ & $=$ & $=$ & $=$ & $=$ & $=$ & $=$ & $=$ & $>$ & $=$ & $=$ & $=$ & $>$ & $>$ \\
\hline 3 & $=$ & $=$ & $=$ & $=$ & $=$ & $=$ & $=$ & $=$ & $>$ & $=$ & $=$ & $=$ & $=$ & $=$ \\
\hline 4 & $=$ & $<$ & $>$ & $=$ & $=$ & $=$ & $<$ & $=$ & $>$ & $<$ & $=$ & $<$ & $=$ & $<$ \\
\hline 5 & $=$ & $=$ & $=$ & $=$ & $=$ & $=$ & $=$ & $=$ & $>$ & $=$ & $=$ & $=$ & $>$ & $=$ \\
\hline 6 & $=$ & $=$ & $>$ & $=$ & $=$ & $=$ & $>$ & $=$ & $>$ & $>$ & $>$ & $=$ & $=$ & $=$ \\
\hline 7 & $<$ & $=$ & $>$ & $=$ & $<$ & $=$ & $=$ & $=$ & $>$ & $=$ & $<$ & $<$ & $>$ & $>$ \\
\hline 8 & $=$ & $=$ & $=$ & $=$ & $=$ & $<$ & $=$ & $=$ & $=$ & $=$ & $=$ & $=$ & $=$ & $=$ \\
\hline 9 & $<$ & $=$ & $=$ & $=$ & $<$ & $=$ & $=$ & $<$ & $=$ & $=$ & $<$ & $=$ & $=$ & $<$ \\
\hline 10 & $<$ & $=$ & $<$ & $=$ & $<$ & $=$ & $<$ & $<$ & $<$ & $=$ & $<$ & $<$ & $=$ & $>$ \\
\hline 21 & $=$ & $=$ & $=$ & $=$ & $=$ & $=$ & $=$ & $=$ & $=$ & $=$ & $=$ & $=$ & $=$ & $>$ \\
\hline 41 & $<$ & $=$ & $>$ & $<$ & $<$ & $=$ & $<$ & $=$ & $>$ & $=$ & $<$ & $<$ & $>$ & $<$ \\
\hline 42 & $<$ & $=$ & $<$ & $<$ & $<$ & $=$ & $<$ & $=$ & $>$ & $=$ & $<$ & $<$ & $=$ & $<$ \\
\hline 43 & $=$ & $=$ & $=$ & $<$ & $=$ & $<$ & $=$ & $=$ & $=$ & $=$ & $=$ & $=$ & $=$ & $=$ \\
\hline 44 & $=$ & $=$ & $=$ & $=$ & $=$ & $=$ & $=$ & $=$ & $=$ & $=$ & $=$ & $=$ & $=$ & $>$ \\
\hline 49 & $=$ & $=$ & $=$ & $=$ & $=$ & $>$ & $=$ & $=$ & $=$ & $=$ & $=$ & $=$ & $=$ & $=$ \\
\hline $\mathrm{MO}$ & $=$ & $=$ & $=$ & $=$ & $=$ & $=$ & $=$ & $=$ & $=$ & $=$ & $=$ & $=$ & $=$ & $=$ \\
\hline
\end{tabular}

$N^{\circ}$ : numéro de souche; T : Témoin; GA : Galactose; MA : Maltose; LA : Lactose; ER : Erythritol; RI : D-ribose; AR : Arabinose; RA : Raffinose; AM : Amidon; XY : Xylose; SA : Salicine; RH : L-Rhamnose; AE : Aesculine; GL : Glycérol.

teur (R : souche résistante, $\mathrm{S}$ : souche sensible, I : souche intermédiaire) (Bauer et al, 1966; Ferron, 1974) (tableaux V et VI). Deux répétitions par souche et par antibiotique sont effectuées.

\section{La méthode d'analyse}

\section{Le tableau de données}

Les variables caractérisant les souches sont, soit quantitatives (agressivité), soit qualitatives (lysotypie), soit enfin qualitatives ordonnées (croissance sur différents substrats et sensibilité aux antibiotiques). La méthode utilisée ne permet pas de prendre en compte directement les variables qualitatives ordonnées. Aussi elles seront considérées comme qualitatives et introduites au travers du codage disjonctif complet. Ce codage fait apparaître des modalités très rares : les modalités comportant moins de 4 individus ont été éliminées, soit par regroupement entre modalités voisines, soit par suppression de l'ensemble des modalités associées au substrat ou à l'antibiotique concerné. Compte tenu de ces pertes d'informations, et afin de permettre une évaluation a posteriori de l'influence de ces modifications, les variables de ces 2 groupes sont aussi introduites dans leur codage initial, c'est-à-dire sous forme de notes. Enfin, l'origine géographique des souches est notée à l'aide d'une variable qualita- tive indiquant la région dans laquelle la souche a été isolée.

Finalement, le tableau de données comporte, en lignes, 54 individus et en colonnes 95 variables réparties en 7 groupes (tableau VII).

Quatre groupes sont considérés dans la suite comme actifs :

- groupe 1 : variables «agressivité" (numériques);

- groupe 2 : variables «lysotypie» (qualitatives);

- groupe 3 : variables "croissance sur différents substrats" (qualitatives);

- groupe 4 : variables "sensibilité aux antibiotiques" (qualitatives).

Trois groupes sont considérés dans la suite comme supplémentaires :

- groupe 5 : variables «croissance sur différents substrats" (numériques);

- groupe 6 : variables «sensibilité aux antibiotiques" (numériques);

- groupe 7 : origine géographique (variable qualitative).

\section{Objectifs et méthode utilisée}

L'objectif général de description de la variabilité des souches peut être articulé autour de 3 thèmes principaux. 
Tableau V. Sensibilité des souches de $X c p v$ manihotis aux antibiotiques. S : l'ensemble des souches est sensible à l'antibiotique, R : l'ensemble des souches est résistant à l'antibiotique, I : l'ensemble des souches a une sensibilité «intermédiaire» à l'antibiotique, $\mathrm{V}$ : les souches ont une sensibilité variable à l'antibiotique.

\begin{tabular}{|c|c|c|c|c|}
\hline Famille & $\begin{array}{l}\text { Dénomination } \\
\text { commune }\end{array}$ & $\begin{array}{l}\text { Sigle du } \\
\text { disque }\end{array}$ & $\begin{array}{c}\text { Charge du } \\
\text { disque }\end{array}$ & $\begin{array}{c}\text { Réaction de } \\
X \mathrm{cv} p v \text { manihotis }\end{array}$ \\
\hline \multirow[t]{17}{*}{ Béta lactamines } & $\begin{array}{l}\text { Pénicilline G } \\
\text { Pénicillines A }\end{array}$ & PEN & $6 \mu \mathrm{g}(10 \mathrm{UI})$ & $v$ \\
\hline & Ampicilline & AMP & $10 \mu \mathrm{g}$ & v \\
\hline & Amoxicilline & AMO & $25 \mu \mathrm{g}$ & V \\
\hline & Carbénicilline & CAR & $100 \mu \mathrm{g}$ & $\mathrm{s}$ \\
\hline & Ticarcilline & TIC & $75 \mu \mathrm{g}$ & V \\
\hline & Pénicillines M & & & \\
\hline & Méticilline & MET & $5 \mu \mathrm{g}$ & $\mathrm{R}$ \\
\hline & Oxacilline & OXA & $5 \mu \mathrm{g}$ & $\mathrm{s}$ \\
\hline & Céphalosporines & & & \\
\hline & Céfradine & CFA & $30 \mu \mathrm{g}$ & $\mathbf{R}$ \\
\hline & Céfalotine & CTN & $30 \mu \mathrm{g}$ & v \\
\hline & Céfaloridine & CFR & $30 \mu \mathrm{g}$ & V \\
\hline & Céfazoline & $\mathrm{CFZ}$ & $30 \mu \mathrm{g}$ & $\mathrm{R}$ \\
\hline & Céfotaxime & CTX & $30 \mu \mathrm{g}$ & $\mathrm{v}$ \\
\hline & Céfuroxime & CXM & $30 \mu \mathrm{g}$ & $\mathrm{v}$ \\
\hline & Céfoxitime & CXT & $30 \mu \mathrm{g}$ & $\mathrm{v}$ \\
\hline & Latamoxef & MOX & $30 \mu \mathrm{g}$ & $\mathrm{s}$ \\
\hline \multirow[t]{9}{*}{ Aminosides } & Streptomycine & STR & $10 \mathrm{UI}$ & $\mathrm{s}$ \\
\hline & Kanamycine & KAN & $30 \mathrm{UI}$ & $\mathrm{s}$ \\
\hline & Néomycine & NEO & $30 \mathrm{UI}$ & 1 \\
\hline & Framycétine & FRA & $30 \mathrm{UI}$ & I \\
\hline & Paromycine & PAR & $30 \mathrm{UI}$ & $s$ \\
\hline & Tobramycine & TOB & $10 \mu \mathrm{g}$ & s \\
\hline & Amikacine & AKN & $30 \mu \mathrm{g}$ & $s$ \\
\hline & Gentamicine & GEN & $15 \mu \mathrm{g}(10 \mathrm{Ul})$ & $\mathrm{s}$ \\
\hline & Sisomicine & SIS & $10 \mu \mathrm{g}$ & $s$ \\
\hline \multirow[t]{2}{*}{ Phénicoles } & Chloramphénicol & CMP & $30 \mu \mathrm{g}$ & $\mathrm{s}$ \\
\hline & Thiamphénicol & THI & $30 \mu \mathrm{g}$ & $R$ \\
\hline \multirow[t]{5}{*}{ Tétracyclines } & Chortétracycline & CLT & $30 \mathrm{UI}$ & $\mathrm{s}$ \\
\hline & Oxytétracycline & OXT & $30 \mathrm{UI}$ & S \\
\hline & Déoxycycline & DOT & $30 \mathrm{UI}$ & $s$ \\
\hline & Minocycline & MIN & $30 \mathrm{UI}$ & $s$ \\
\hline & DMCT & DMT & $30 \mathrm{UI}$ & s \\
\hline \multirow[t]{9}{*}{ Macrolides } & Macrolides & & & \\
\hline & Erythromycine & ERY & $15 \mathrm{UI}$ & $s$ \\
\hline & Spiramycine & $\mathrm{SPI}$ & $100 \mu \mathrm{g}(333 \mathrm{UI})$ & $s$ \\
\hline & Midécamycine & MID & $100 \mu \mathrm{g}(333 \mathrm{UI})$ & v \\
\hline & Lincosamides & & & \\
\hline & Lincomycine & LIN & $15 \mu \mathrm{g}$ & $\mathbf{R}$ \\
\hline & Streptogramines & & & \\
\hline & Virginiamycine & VIR & $15 \mu \mathrm{g}$ & v \\
\hline & Pristinamycine & PRI & $15 \mu \mathrm{g}$ & $\mathrm{s}$ \\
\hline Polypeptides & Bacitracine & $\mathrm{BAC}$ & $130 \mu \mathrm{g}(10 \mathrm{UI})$ & $s$ \\
\hline Nitro-furanes & Furanes & FUR & $300 \mu \mathrm{g}$ & v \\
\hline \multirow[t]{2}{*}{ Quinolones } & Acide nalidixique & NAL & $30 \mu \mathrm{g}$ & i \\
\hline & Acide pipémidique & $\mathrm{Pl}$ & $20 \mu \mathrm{g}$ & S \\
\hline \multirow{6}{*}{$\begin{array}{l}\text { Antibactériens } \\
\text { divers }\end{array}$} & Rifampicine & RFA & $30 \mathrm{Mg}$ & $\mathrm{s}$ \\
\hline & Novobiocine & NOV & 30 UI & $s$ \\
\hline & Nitroxoline & NIB & $20 \mu \mathrm{g}$ & S \\
\hline & Fosfomycine & FOS & $50 \mu \mathrm{g}$ & $\mathrm{R}$ \\
\hline & Vancomycine & VAN & $30 \mu \mathrm{g}$ & s \\
\hline & Métronidazole & MOL & $4 \mu \mathrm{g}$ & $\mathrm{R}$ \\
\hline
\end{tabular}


Tableau VI. Réponses des souches $X c$ pv manihotis aux antibiotiques, présentant une variabilité.

$S$ : la souche est sensible à l'antibiotique. $R$ : la souche est résistante à l'antibiotique. l: la souche possède une résistance intermédiaire.

PEN AMP AMO TIC MZ CTN CFR CTX CXM CXT MID VIR FUR

\begin{tabular}{|c|c|c|c|c|c|c|c|c|c|c|c|c|c|}
\hline 1 & $R$ & 1 & $R$ & $R$ & R & $S$ & $R$ & 1 & $R$ & 1 & $R$ & R & $R$ \\
\hline 2 & 1 & $S$ & $R$ & $S$ & $\mathbf{R}$ & 1 & $\mathbf{R}$ & 1 & $R$ & I & $R$ & $R$ & $R$ \\
\hline 3 & $\mathbf{R}$ & R & $R$ & $S$ & $\mathbf{R}$ & 1 & $\mathbf{R}$ & 1 & $\mathrm{R}$ & 1 & $\mathbf{R}$ & R & $R$ \\
\hline 4 & 1 & $S$ & $S$ & $S$ & $S$ & 1 & $S$ & $S$ & $S$ & $S$ & $S$ & $\mathbf{R}$ & $R$ \\
\hline 5 & 1 & 1 & $\mathrm{R}$ & $S$ & $\mathrm{R}$ & 1 & $\mathbf{R}$ & 1 & $\mathbf{R}$ & 1 & $R$ & $R$ & $R$ \\
\hline 6 & $\mathbf{R}$ & $R$ & $R$ & $\mathbf{R}$ & $R$ & 1 & $\mathbf{R}$ & 1 & $\mathrm{R}$ & 1 & $\mathbf{R}$ & $R$ & $R$ \\
\hline 7 & $R$ & 1 & $\mathrm{~S}$ & $\mathrm{~S}$ & $R$ & 1 & $\mathrm{R}$ & $S$ & $\mathrm{R}$ & $\mathrm{S}$ & $\mathrm{R}$ & $R$ & $R$ \\
\hline 8 & $R$ & $R$ & $R$ & $S$ & 1 & 1 & $\mathbf{R}$ & I & $R$ & 1 & $\mathbf{R}$ & $R$ & $R$ \\
\hline 9 & 1 & $S$ & $S$ & $S$ & $S$ & 1 & $S$ & $S$ & $S$ & $S$ & $S$ & $S$ & 1 \\
\hline 10 & 1 & 1 & $R$ & $S$ & $S$ & 1 & $\mathbf{R}$ & 1 & $R$ & 1 & $\mathbf{R}$ & $\mathbf{R}$ & 1 \\
\hline 11 & $R$ & R & $R$ & $S$ & 1 & 1 & $R$ & 1 & $R$ & 1 & $\mathbf{R}$ & $R$ & $R$ \\
\hline 12 & $\mathrm{R}$ & $\mathrm{R}$ & $\mathrm{R}$ & $\mathrm{R}$ & $\mathrm{R}$ & 1 & $\mathbf{R}$ & 1 & $R$ & 1 & $R$ & $\mathbf{R}$ & $\mathrm{R}$ \\
\hline 13 & $\mathbf{R}$ & $R$ & $R$ & $R$ & $R$ & $\mathbf{R}$ & $\mathbf{R}$ & 1 & $R$ & 1 & $\mathbf{R}$ & $\mathbf{R}$ & $R$ \\
\hline 14 & $R$ & R & $R$ & $S$ & $R$ & 1 & $R$ & 1 & $\mathrm{R}$ & 1 & $R$ & $R$ & $R$ \\
\hline 15 & $\mathrm{R}$ & $\mathbf{R}$ & $\mathbf{R}$ & $S$ & $\mathbf{R}$ & 1 & $R$ & 1 & $\mathrm{R}$ & 1 & $\mathbf{R}$ & $\mathbf{R}$ & $R$ \\
\hline 16 & $\mathrm{R}$ & $\mathbf{R}$ & R & $S$ & $R$ & 1 & $R$ & 1 & R & I & $\mathbf{R}$ & $\mathrm{R}$ & $\mathrm{R}$ \\
\hline 17 & $R$ & $\mathbf{R}$ & $\mathbf{R}$ & $S$ & $\mathrm{R}$ & 1 & $R$ & 1 & $R$ & 1 & $R$ & $R$ & $R$ \\
\hline 18 & R & $R$ & $R$ & $S$ & $S$ & 1 & $\mathbf{R}$ & 1 & $R$ & 1 & $\mathbf{R}$ & $R$ & $R$ \\
\hline 19 & $R$ & R & $R$ & $R$ & $R$ & $S$ & $R$ & 1 & $\mathbf{R}$ & 1 & $\mathbf{R}$ & $\mathrm{R}$ & $\mathrm{R}$ \\
\hline 20 & R & 1 & 1 & $S$ & $R$ & $S$ & I & 1 & $\mathrm{R}$ & 1 & $\mathbf{R}$ & $\mathrm{R}$ & $\mathrm{R}$ \\
\hline 21 & $\mathbf{R}$ & $\mathbf{R}$ & $\mathbf{R}$ & $\mathbf{R}$ & $\mathrm{R}$ & 1 & $R$ & 1 & $R$ & I & $\mathbf{R}$ & $R$ & $\mathrm{R}$ \\
\hline 22 & $\mathrm{R}$ & $\mathbf{R}$ & $\mathbf{R}$ & $S$ & 1 & I & $\mathrm{R}$ & I & $\mathbf{R}$ & I & $R$ & $R$ & $R$ \\
\hline 23 & $R$ & $\mathbf{R}$ & $\mathbf{R}$ & $R$ & $R$ & I & $R$ & I & $\mathbf{R}$ & I & $\mathrm{R}$ & $R$ & $R$ \\
\hline 24 & R & $\mathbf{R}$ & $\mathbf{R}$ & $\mathrm{R}$ & $R$ & I & $R$ & I & $\mathbf{R}$ & I & $R$ & $\mathrm{R}$ & $R$ \\
\hline 25 & $R$ & $\mathbf{R}$ & $R$ & $\mathrm{R}$ & $\mathrm{R}$ & 1 & $\mathrm{R}$ & I & $R$ & 1 & $\mathrm{R}$ & $R$ & $R$ \\
\hline 26 & $R$ & $\mathbf{R}$ & $R$ & $S$ & 1 & 1 & $\mathbf{R}$ & 1 & $\mathbf{R}$ & 1 & $R$ & $R$ & R \\
\hline 27 & $\mathbf{R}$ & $\mathbf{R}$ & $\mathbf{R}$ & $S$ & $R$ & 1 & $R$ & 1 & $\mathbf{R}$ & 1 & $\mathbf{R}$ & R & $R$ \\
\hline 28 & $\mathbf{R}$ & $\mathbf{R}$ & $\mathbf{R}$ & $R$ & $\mathrm{R}$ & 1 & $R$ & 1 & $R$ & 1 & $\mathrm{R}$ & $R$ & $R$ \\
\hline 29 & R & $\mathbf{R}$ & $\mathrm{R}$ & R & R & 1 & $R$ & 1 & $R$ & 1 & $\mathrm{R}$ & $R$ & $R$ \\
\hline 30 & $\mathbf{R}$ & $\mathbf{R}$ & R & $\mathbf{R}$ & $\mathbf{R}$ & I & $\mathbf{R}$ & 1 & $R$ & 1 & $\mathbf{R}$ & $\mathrm{R}$ & 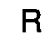 \\
\hline 31 & $\mathbf{R}$ & $\mathbf{R}$ & $\mathbf{R}$ & R & $\mathrm{R}$ & 1 & $\mathrm{R}$ & 1 & $R$ & I & $\mathbf{R}$ & $R$ & $R$ \\
\hline 32 & $\mathrm{R}$ & $R$ & $\mathbf{R}$ & $\mathrm{R}$ & $\mathrm{R}$ & 1 & $\mathrm{R}$ & I & $\mathrm{R}$ & I & $\mathrm{R}$ & $\mathrm{R}$ & $R$ \\
\hline 33 & $R$ & $\mathrm{R}$ & $\mathbf{R}$ & $S$ & $R$ & I & $\mathrm{R}$ & I & $R$ & I & $\mathbf{R}$ & $R$ & $R$ \\
\hline 34 & $R$ & $\mathbf{R}$ & $\mathbf{R}$ & $S$ & $\mathrm{R}$ & I & $\mathrm{R}$ & I & $\mathbf{R}$ & I & $\mathrm{R}$ & $R$ & $R$ \\
\hline 35 & $\mathbf{R}$ & $\mathrm{R}$ & $\mathbf{R}$ & R & 1 & I & $\mathrm{R}$ & 1 & $\mathbf{R}$ & 1 & $\mathrm{R}$ & $\mathrm{R}$ & $\mathbf{R}$ \\
\hline 36 & $\mathbf{R}$ & 1 & $\mathbf{R}$ & $R$ & $\mathbf{R}$ & 1 & $\mathbf{R}$ & 1 & $\mathbf{R}$ & 1 & $\mathrm{R}$ & $R$ & $\mathbf{R}$ \\
\hline 37 & $\mathbf{R}$ & 1 & 1 & $R$ & $R$ & $S$ & 1 & $S$ & $\mathbf{R}$ & $S$ & $R$ & R & $R$ \\
\hline 38 & 1 & $R$ & $\mathbf{R}$ & $S$ & $S$ & 1 & R & 1 & 1 & 1 & $\mathrm{R}$ & $\mathbf{R}$ & $\mathbf{R}$ \\
\hline 39 & $\mathbf{R}$ & 1 & $\mathbf{R}$ & $\mathbf{R}$ & $\mathbf{R}$ & 1 & $\mathbf{R}$ & I & $\mathbf{R}$ & I & $\mathrm{R}$ & $R$ & $\mathbf{R}$ \\
\hline 40 & $\mathbf{R}$ & 1 & $\mathbf{R}$ & $S$ & $S$ & 1 & $R$ & $\mathrm{~S}$ & $\mathbf{R}$ & $S$ & $R$ & $R$ & $R$ \\
\hline 41 & I & $S$ & $S$ & $S$ & 1 & 1 & $\mathbf{R}$ & $S$ & $S$ & $S$ & $S$ & $R$ & $R$ \\
\hline 42 & $\mathbf{R}$ & $R$ & $R$ & $\mathrm{~S}$ & $R$ & 1 & $R$ & 1 & $R$ & 1 & $R$ & $R$ & R \\
\hline 43 & $\mathbf{R}$ & 1 & $\mathbf{R}$ & $S$ & $S$ & 1 & $\mathbf{R}$ & $S$ & 1 & $S$ & $\mathbf{R}$ & $\mathbf{R}$ & $R$ \\
\hline 44 & $R$ & $R$ & $\mathbf{R}$ & $\mathbf{R}$ & $\mathbf{R}$ & 1 & $R$ & I & $\mathbf{R}$ & I & $\mathrm{R}$ & $R$ & R \\
\hline 45 & $\mathbf{R}$ & $R$ & $\mathrm{R}$ & $\mathrm{R}$ & $\mathbf{R}$ & 1 & $\mathrm{R}$ & 1 & $\mathbf{R}$ & 1 & $\mathrm{R}$ & $\mathrm{R}$ & $R$ \\
\hline 46 & $\mathbf{R}$ & $R$ & $\mathbf{R}$ & $\mathbf{R}$ & $\mathbf{R}$ & 1 & $\mathbf{R}$ & I & $\mathbf{R}$ & I & $R$ & $R$ & $R$ \\
\hline 47 & $\mathbf{R}$ & $\mathbf{R}$ & $\mathbf{R}$ & $\mathbf{R}$ & $\mathbf{R}$ & 1 & $\mathbf{R}$ & 1 & $\mathbf{R}$ & 1 & $R$ & $R$ & R \\
\hline 48 & $\mathrm{R}$ & $\mathrm{R}$ & $\mathrm{R}$ & $\mathrm{R}$ & $\mathbf{R}$ & $i$ & $\mathrm{R}$ & $i$ & $\mathrm{R}$ & $i$ & $\mathrm{R}$ & $\mathrm{R}$ & $\mathrm{R}$ \\
\hline 49 & $R$ & $R$ & $\mathrm{R}$ & $R$ & $R$ & 1 & $R$ & 1 & $\mathrm{R}$ & 1 & $R$ & $R$ & $R$ \\
\hline 50 & I & $S$ & $S$ & $\mathrm{~S}$ & $S$ & 1 & $R$ & $S$ & $R$ & $S$ & $R$ & $\mathrm{R}$ & $R$ \\
\hline 51 & $\mathbf{R}$ & $R$ & $R$ & $\mathbf{R}$ & $R$ & 1 & $R$ & 1 & $R$ & 1 & $R$ & $\mathbf{R}$ & $R$ \\
\hline 52 & $R$ & $R$ & $\mathrm{R}$ & $\mathrm{R}$ & $R$ & 1 & $R$ & 1 & $R$ & 1 & $R$ & $\mathbf{R}$ & $\mathrm{R}$ \\
\hline 53 & $R$ & $\mathbf{R}$ & $\mathbf{R}$ & $\mathrm{R}$ & $\mathrm{R}$ & 1 & $R$ & 1 & $R$ & 1 & R & $\mathbf{R}$ & $R$ \\
\hline 54 & $R$ & $R$ & $\mathbf{R}$ & $R$ & $R$ & 1 & $\mathbf{R}$ & 1 & $\mathbf{R}$ & 1 & $\mathbf{R}$ & $\mathbf{R}$ & $R$ \\
\hline
\end{tabular}


Tableau VII. Structure du tableau de données.

\begin{tabular}{lccccccc}
\hline & & \multicolumn{2}{c}{ Groupes actifs } & \multicolumn{3}{c}{ Groupes supplémentaires } \\
\hline Groupe & 1 & 2 & 3 & 4 & 5 & 6 & 7 \\
Type & agressivité & lysotypie & substrats & antibioitiques & substrats & antibiotiques & origine \\
$\begin{array}{l}\text { Nombre de } \\
\text { variables }\end{array}$ & 4 & 9 & 9 & 11 & 9 & 11 & 1 \\
$\begin{array}{l}\text { Nombre de } \\
\text { colonnes }\end{array}$ & 4 & 18 & 17 & 24 & 9 & 11 & 10 \\
54 souches & & & & & & & \\
\hline
\end{tabular}

- Quelles sont les souches qui se ressemblent et celles qui diffèrent si l'on considère l'ensemble des 4 caractères (agressivité, lysotypie, croissance sur différents substrats carbonés, sensibilité aux antibiotiques)?

- Quels sont, globalement, les groupes de variables qui se ressemblent ? Deux groupes se ressemblent s'ils induisent la même structure sur l'ensemble des individus, c'est-à-dire si 2 souches proches pour l'un sont aussi proches pour l'autre.

- Même si, globalement, les groupes ne sont pas très proches, certains d'entre eux possèdent-ils des facteurs communs ? Si ces facteurs existent, quels sont-ils et quelle est leur importance relative dans chaque groupe ? (Par facteur, on entend l'ensemble des coordonnées des souches le long d'une direction quelconque d'un espace défini par un ensemble de variables. Un facteur est dit commun à plusieurs groupes s'il est possible de mettre en évidence un facteur dans chacun des groupes tel que les facteurs ainsi trouvés soient fortement corrélés entre eux).

Pour cela, ce tableau peut être traité par l'analyse factorielle multiple (AFM). Cette méthode fournit des résultats qui correspondent aux principaux thèmes de la problématique énoncée précédemment. En effet, elle permet de réaliser l'analyse factorielle d'un ensemble d'individus décrits à la fois par des groupes de variables quantitatives et des groupes de variables qualitatives. Elle construit une représentation graphique des proximités entre groupes et met en évidence, s'ils existent, une suite de facteurs communs aux groupes. Cette méthode est décrite en détail par Escofier et Pagès (1988).

\section{RÉSULTATS}

\section{Les valeurs propres de l'analyse globale}

Le cœur d'une AFM consiste en une ACP centrée réduite des 4 groupes actifs dans laquelle chaque variable est affectée d'un poids destiné à équilibrer l'influence des groupes. Ces 4 groupes permettent de construire un nuage des souches (dans l'espace défini par l'ensemble des colonnes actives) appelé nuage moyen en ce sens qu'il réalise un compromis entre les 4 nuages que l'on peut construire à partir de chacun des groupes.

La première valeur propre vaut 2,5 . On sait que la valeur maximale qu'elle peut atteindre dans le cas limite où ce facteur coïncide avec le premier facteur de l'analyse factorielle séparée de chaque groupe est le nombre de groupes (ici 4). La valeur 2,5 assure que le premier facteur est assez proche d'une direction d'inertie importante de chacun des 4 groupes.

Le diagramme des pourcentages met en évidence un premier facteur important $(35 \%$ de l'inertie totale) et un deuxième beaucoup plus faible ( $10 \%$ de l'inertie totale). Les autres facteurs représentent chacun moins de $8 \%$ de l'inertie totale.

\section{Facteurs communs}

Avant de commenter les représentations issues de cette analyse globale, il convient d'examiner si les résultats constituent effectivement des aspects communs à l'ensemble des 4 thèmes étudiés.

Dans l'AFM, les facteurs de l'ACP globale, appelés variables générales car s'appuyant sur l'ensemble des groupes, jouent le rôle de facteurs communs. La méthode fournit aussi, associée à chaque variable générale, des variables canoniques (une par groupe) qui peuvent être considérées comme l'expression du facteur commun dans chacun des groupes. Techniquement, ces variables canoniques sont des projections 
des nuages de souches caractérisés chacun uniquement par un groupe, qui, à la fois, correspondent à des directions d'inertie importante et sont liées au facteur commun.

Le tableau des corrélations entre les variables canoniques et les variables générales (tableau VIII), indique, pour chaque groupe actif, les corrélations entre chaque facteur du nuage moyen et l'expression de ce facteur dans ce groupe. Pour le premier facteur, ces corrélations qui valent respectivement 0,$822 ; 0,714 ; 0,824 ; 0,822$ sont assez élevées pour que l'on puisse considérer ce facteur comme commun aux 4 groupes: il existe dans chacun des 4 nuages des souches définies par un seul groupe, une direction dans laquelle la dispersion du nuage res-

Tableau VIII. Corrélation entre les variables canoniques et les variables générales.

0,822 est le coefficient de corrélation entre le premier facteur commun (première variable générale) et son expression dans le groupe 1 (première variable canonique du groupe 1).

Les 4 coefficients associés au premier facteur sont suffisamment élevés pour que l'on puisse considérer ce facteur comme commun aux 4 groupes.

Facteur 1 Facteur 2

\begin{tabular}{cccc}
\hline Variable & Groupe 1 & 0,822 & 0,454 \\
canonique & Groupe 2 & 0,714 & 0,661 \\
associée au & Groupe 3 & 0,824 & 0,490 \\
& Groupe 4 & 0,822 & 0,461 \\
\hline
\end{tabular}

Tableau IX. Coefficients de corrélation entre la première variable générale de l'AFM et les 3 premiers facteurs de l'analyse factorielle séparée de chacun des groupes.

\section{Facteur 1 Facteur 2 Facteur 3}

\begin{tabular}{llll}
\hline Groupe 1 & $-0,811$ & $+0,167$ & $+0,006$ \\
Groupe 2 & $+0,710$ & $+0,038$ & $+0,009$ \\
Groupe 3 & $-0,819$ & $+0,073$ & $+0,078$ \\
Groupe 4 & $+0,813$ & $-0,061$ & $+0,018$ \\
Groupe 5 & $-0,755$ & $+0,256$ & $-0,134$ \\
Groupe 6 & $+0,824$ & $-0,067$ & $-0,006$ \\
\hline
\end{tabular}

La première variable générale est liée au premier facteur de chacun des groupes. L'analyse factorielle de chaque groupe consiste en une ACP ou une ACM selon la nature des variables. semble au facteur commun de l'ACP globale pondérée. Par ailleurs, seul le groupe 2 est corrélé au deuxième facteur qui n'est donc pas un facteur commun.

Une autre façon d'évaluer le caractère commun de la variable générale consiste à calculer le coefficient de corrélation entre cette variable générale et les principaux facteurs fournis par l'analyse factorielle séparée de chacun des groupes (tableau $\mathrm{IX}$ ). On remarque que le premier facteur de l'analyse finale est très corrélé au premier facteur de chaque analyse séparée.

\section{Coordonnées et aides à l'interprétation des groupes actifs et supplémentaires}

Les 7 groupes peuvent être représentés dans un espace euclidien par des points dont la proximité traduit la ressemblance entre les structures définies sur l'ensemble des souches. A la limite, 2 points sont confondus si les nuages de souches associés à chacun des 2 groupes sont identiques ou homothétiques. Le graphique de la figure 1 donne une image approchée du nuage par ces 7 points. Sur ce graphique, la coordonnée d'un groupe $j$ le long de l'axe $s$ est aussi égale à la contribution du groupe $j$ à l'axe $s$ de l'analyse globale. II en résulte que ce graphique

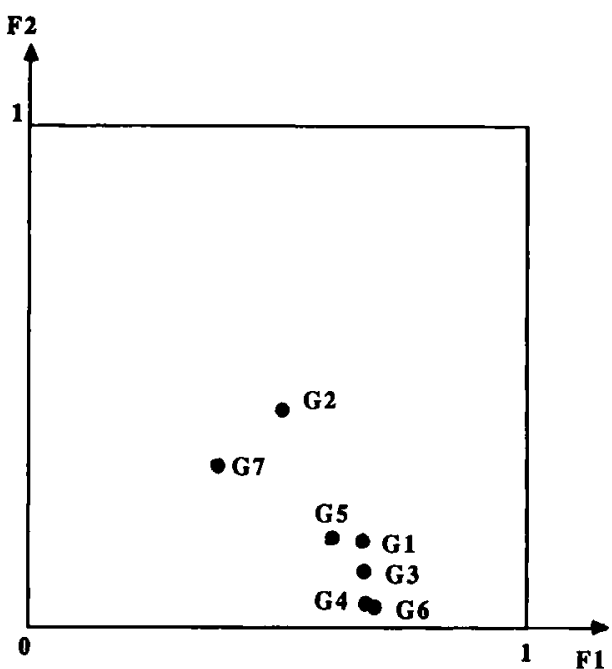

Fig 1. Représentation des groupes par les 2 premiers axes factoriels. G1 : «agressivité" (variables numériques); G2 : "lysotypie" (variables qualitatives); G3 : "croissance sur différents substrats" (variables qualitatives); G4 : "sensibilité aux antibiotiques" (variables qualitatives); G5 : «croissance sur différents substrats" (variables numériques); G6 : "sensibilité aux antibiotiques" (variables numériques); G7 : "origine géographique" (variables qualitatives). La proximité entre 2 groupes s'interprète comme une ressemblance entre les structures sur les individus définies par chacun des groupes. Par construction les coordonnées sont comprises entre 0 et 1 . 
permet d'apprécier non seulement des ressemblances entre groupes mais aussi l'importance de chaque groupe dans la construction des facteurs de l'analyse globale des groupes.

Hormis le groupe 7, tous les groupes présentent une forte coordonnée le long de l'axe 1, ce qui entérine l'existence d'un facteur commun important dans chacun des groupes. Sur cette fig 1 , les groupes 3 et 5 , d'une part, et les groupes 4 et 6 , d'autre part, sont très proches. Rappelons qu'ils concernent les mêmes thèmes sous la forme de codages différents. Le recodage n'a pas bouleversé la structure des individus.

\section{Les variables (fig 2)}

Sur ce graphique, les coordonnées des variables sur un axe sont les coefficients de corrélation entre les variables et les axes.

Les variables les plus corrélées au premier facteur sont :

- Agressivité :

Sur tiges du cultivar M'Pembé : T : MP

Sur tiges du cultivar Koussakanandi : $T: K$

Sur feuilles du cultivar M'Pembé : $F$ : MP

Ces variables sont corrélées positivement au premier facteur.

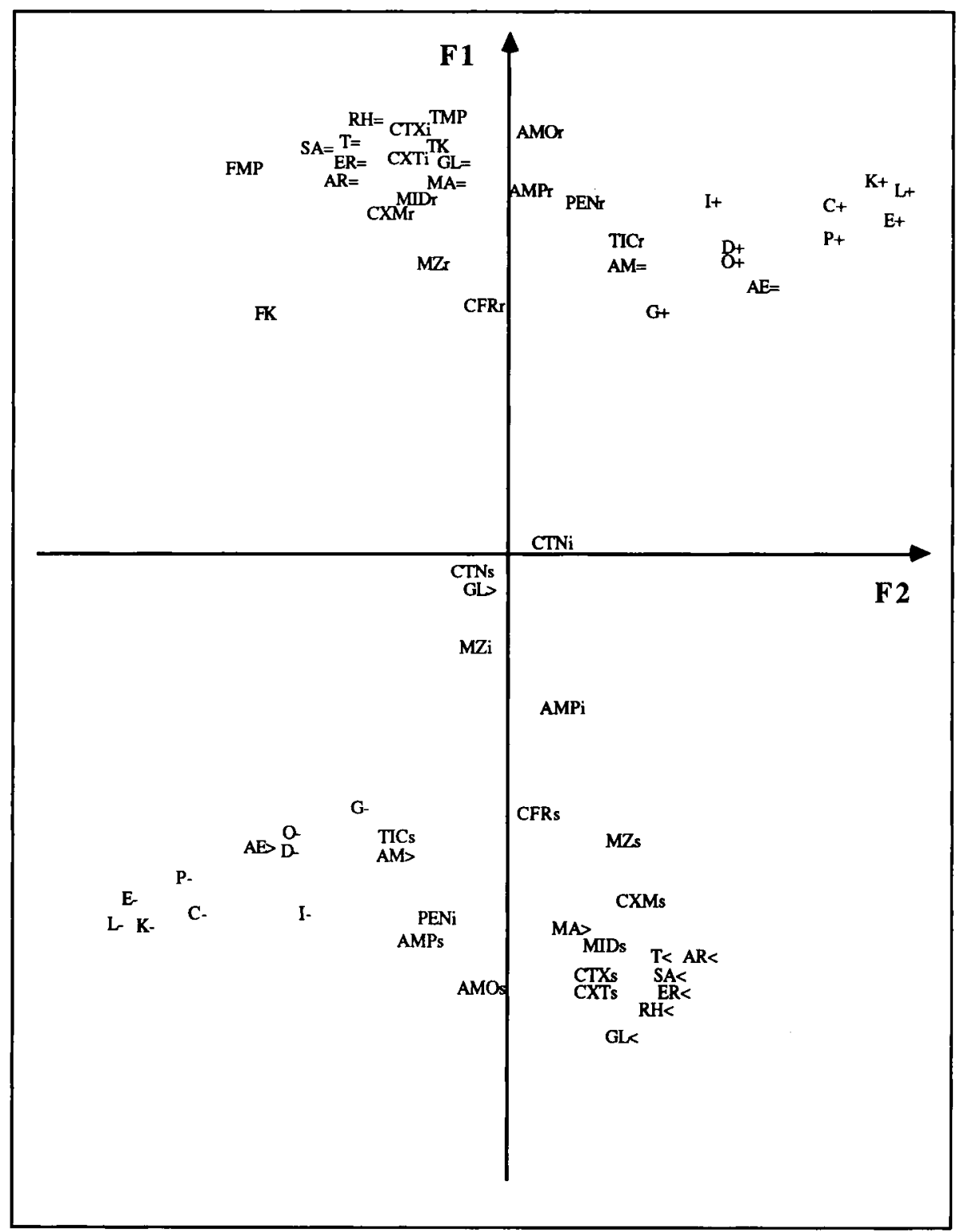

Fig 2. Représentation des variables actives sur le premier plan factoriel. La coordonnée d'une variable est le coefficient de corrélation avec cet axe. 
- Lysotypie :

- Corrélation négative avec le premier facteur

Résistance au phage $\mathrm{K}: \mathrm{K}^{-}$

Résistance au phage $L^{~: ~} L^{-}$

Résistance au phage $\mathrm{C}: \mathrm{C}^{-}$

Résistance au phage $1: 1^{-}$

- Corrélation positive avec le premier facteur

Sensibilité au phage $\mathrm{K}: \mathrm{K}^{+}$

Sensibilité au phage $L: L^{+}$

Sensibilité au phage $\mathrm{C}: \mathrm{C}^{+}$

Sensibilité au phage I: $\mathrm{I}^{+}$

- Croissance sur différents substrats :

- Corrélation négative avec le premier facteur

Glycérol : GL<

Rhamnose : $\mathrm{RH}<$

Témoin : $T<$

Erythritol : ER<

Salicine : $S A<$

Arabinose : AR<

Maltose : MA>

- Corrélation positive avec le premier facteur

Gylcérol : $\mathrm{GL}=$

Rhamnose : $\mathrm{RH}=$

Témoin : $T=$

Erythritol : ER=

Salicine : $S A=$

Arabinose $: A R=$

Maltose : $M A=$

- Sensibilité aux antibiotiques

- Corrélation négative avec le premier facteur

$S$ à la Céfuroxine : CXMs

$S$ à l'Amoxicilline: AMOs

$S$ à la Céfotaxime : CTXs

$S$ à l'Ampicilline : AMPs

$S$ à la Midécamycine : MIDs

- Corrélation positive avec le premier facteur

I à la Céfuroxine : $\mathrm{CXMr}$

$R$ à l'Amoxicilline : AMOr

I à la Céfotaxime : CTXi

$R$ à l'Ampicilline : AMPr

R à la Midécamycine : MIDr

L'axe 1 peut être schématisé par les oppositions suivantes :

- Faible agressivité

- Résistance aux phages

- Hétérogénéité pour la croissance sur différents substrats carbonés
- Sensibilité aux antibiotiques

$+$

- Forte agressivité

- Sensibilité aux phages

- Homogénéité pour la croissance sur différents substrats carbonés

- Résistance aux antibiotiques

\section{Les individus}

\section{Le nuage moyen (fig 3)}

Les règles d'interprétation de la représentation du nuage moyen sont exactement celles de I'ACP. On considère les individus selon leur position sur l'axe 1.

Schématiquement, l'axe 1 oppose les 6 souches $41,4,7,9,42,10$ aux autres souches. Cependant, la différence d'inertie entre les 2 premiers axes est telle que cet axe reste, même sans ces souches.

On peut illustrer la signification de l'axe 1 par quelques exemples: d'une part les souches 41 , 4 et 7 présentant les coordonnées négatives les plus grandes en valeur absolue, et, d'autre part, les souches 24,13 et 14 présentant les coordonnées positives les plus grandes.

Les souches du premier groupe $(41,4,7)$ sont faiblement $(7)$ ou très faiblement $(41,4)$ agressives. Elles sont résistantes à au moins 7 phages. Leur croissance est hétérogène pour au moins 7 substrats. Elles sont sensibles à au moins 5 antibiotiques.

A l'opposé sur l'axe 1, les souches 24,13 et 14 sont très agressives. Elles sont sensibles à au moins 8 phages. Leur croissance est classée homogène sur 9 substrats. Elles sont résistantes à au moins 10 antibiotiques. Ces 3 souches s'opposent aux 3 souches précédentes (41, 4 et 7 ) du point de vue de chaque groupe.

L'hétérogénéité des souches croît des coordonnées positives aux coordonnées négatives. La répartition des souches sur le plan suggère l'existence d'un ensemble de souches, de coordonnées positives, relativement homogènes selon tous les points de vue. La confrontation de ce plan factoriel avec l'origine des souches (tableau 1) montre que le lieu d'isolement n'est globalement pas lié aux principaux facteurs de variabilité. Toutefois, il existe quelques origines dont les souches sont relativement regroupées (Grousson, 1986). C'est le cas du Zaïre 


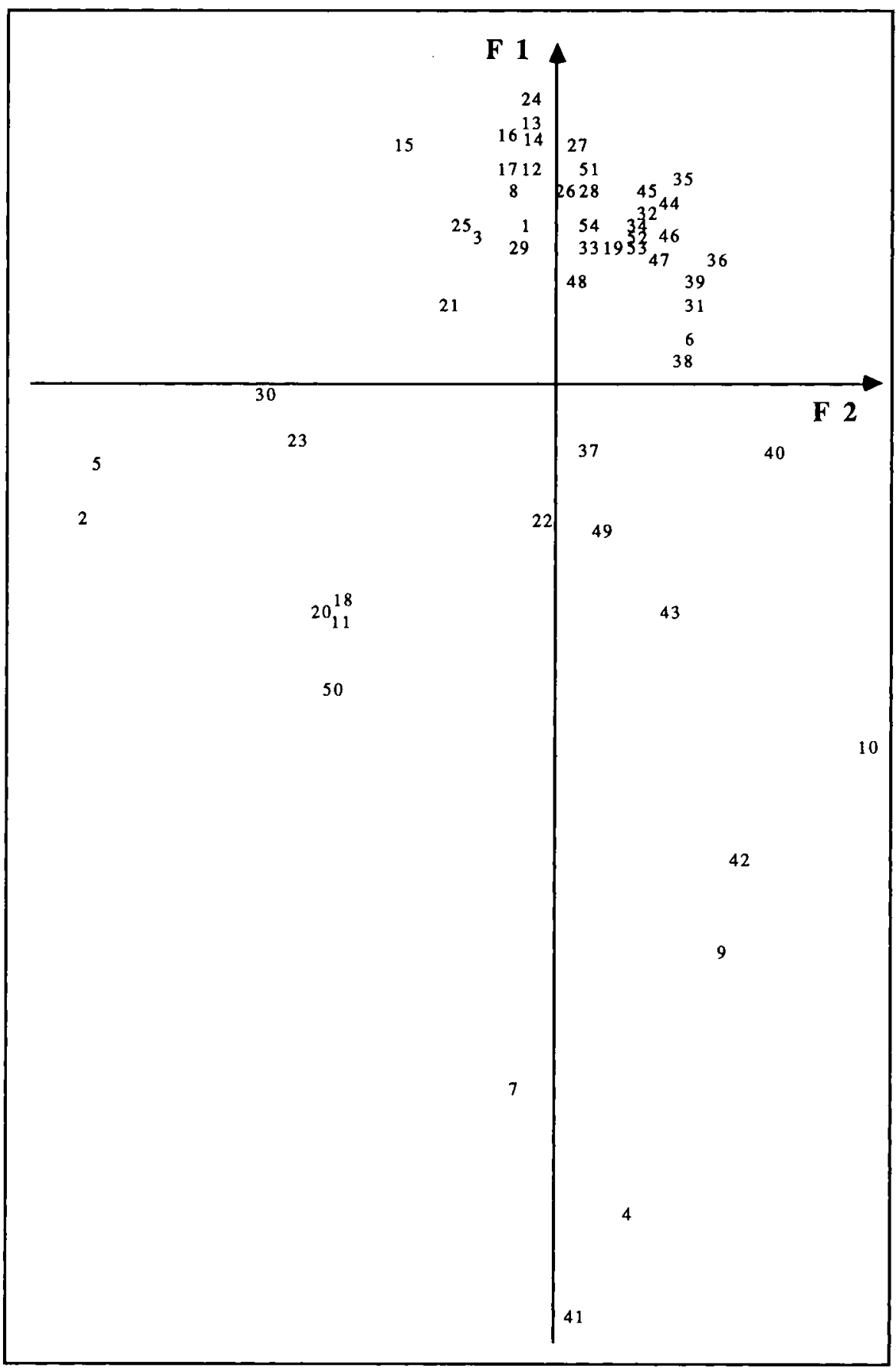

Fig 3. Représentation du nuage moyen des individus sur le plan des deux premiers axes factoriels.

dont 9 souches sur les 11 sont très proches sur le plan 1-2.

\section{La représentation simultanée (fig 4)}

A chaque groupe de variables, on peut associer un nuage des souches. C'est ce nuage qui est approché lors d'une analyse factorielle séparée de chacun des groupes. L'AFM fournit, dans un même cadre, une représentation approchée de chacun des nuages initiaux (fig 3 ). Cette superposition est possible car le premier facteur est bien commun aux différents groupes. Sur un tel graphique, chaque souche est donc représentée 5 fois sur chaque facteur : par sa projection à partir du nuage moyen où elle est définie par l'ensemble des 4 groupes de caractères et par ses projections à partir des 4 nuages définis par un seul groupe de caractères. Seul le premier facteur, commun aux 4 groupes, est intéressant dans cette analyse. Les caractéristiques des 6 


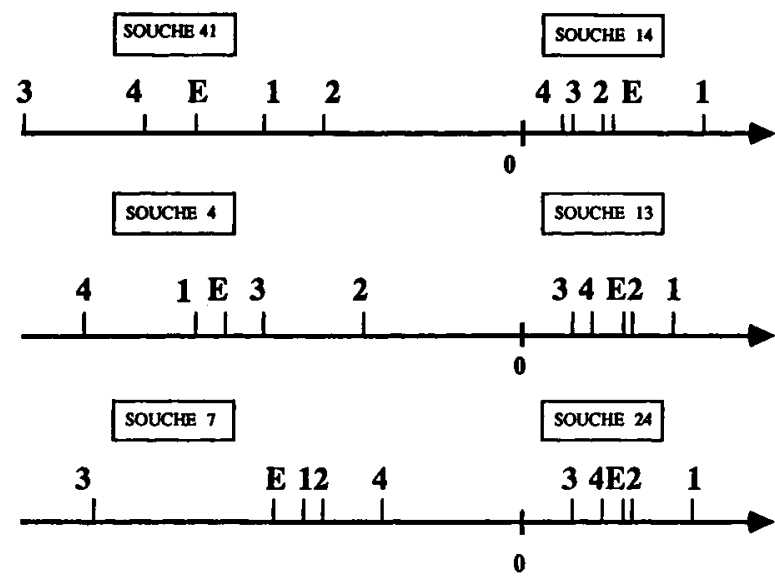

Fig 4. Représentation simultanée des souches $41,4,14,7$, 13 et 24 sur le premier axe factoriel. L'axe est reproduit 3 fois pour éviter des superpositions. $E$ : souche décrite par l'ensemble des groupes des variables. 2 : souche décrite par les seules variables du groupe 2.

souches, $41,4,7,24,13$ et 14, (fig 4) sont résumées par la projection sur l'axe 1 de leurs représentations dans les 4 nuages.

Ainsi, par exemple, la souche 41 est beaucoup plus extrême que la souche 4 du point de vue du groupe 3 (les souches 41 et 4 ont une croissance hétérogène respectivement sur 9 et 7 substrats). Parallèlement, la souche 4 est un peu plus extrême que la souche 41 du point de vue du groupe 4 (les souches 4 et 41 sont sensibles à, respectivement, 9 et 8 antibiotiques).

Le gradient d'hétérogénéité mis en évidence à partir du nuage moyen s'accompagne, parallèlement, d'un gradient d'hétérogénéité au niveau de chacun des groupes. Par exemple, du point de vue du groupe 1 , les souches 14,13 et 24 ont des coordonnées très voisines alors que les souches 41,4 et 7 ont des coordonnées très variables. Cette observation peut être faite pour chacun des groupes.

\section{DISCUSSION ET CONCLUSION}

Le résultat essentiel de cette analyse est la mise en évidence d'une variabilité de Xanthomonas campestris pv manihotis. Cette variabilité apparaît relativement limitée, ce qui explique qu'elle ait pu passer inaperçue. Par exemple, sur 48 antibiotiques testés, seulement 11 mettent en évidence une réponse variable des souches. Par ailleurs, l'analyse montre qu'il existe un groupe de souches homogène et, seul un échantillonnage très diversifié peut montrer une variabilité.
L'étude multidimentionnelle de cette variabilité permet de mettre en évidence un facteur commun à l'ensemble des groupes de variables. L'existence de ce facteur commun suscite plusieurs hypothèses qui doivent être examinées au travers des liaisons les plus chargées de sens.

Une sélection naturelle peut rendre compte de la liaison positive entre l'agressivité et la résistance aux antibiotiques. En effet, d'une part, une souche agressive est plus adaptée à l'hôte qu'une souche peu agressive. Elle se multiplie mieux, migre plus rapidement dans les tissus de l'hôte, est capable de surmonter certains mécanismes de défense de la plante. En ce sens, l'agressivité est un critère de sélection naturelle. D'autre part, au moment de sa dissémination, Xanthomonas campestris pv manihotis connaît une phase épiphyte où il est en compétition avec d'autres micro-organismes présents sur les feuilles. Certains synthétisent des antibiotiques. En ce sens, la résistance aux antibiotiques est aussi un critère de sélection naturelle. L'hypothèse d'une sélection de souches résistantes à ces antibiotiques pourrait être testée par la recherche et l'isolement de micro-organismes épiphytes antagonistes et par l'étude des substances qu'ils sont susceptibles de synthétiser.

La liaison entre l'agressivité et la résistance aux antibiotiques d'une part, et la sensibilité aux phages d'autre part, ne semble pas pouvoir être expliquée par un mécanisme physiologique au niveau de Xanthomonas campestris pv manihotis mais par un phénomène de lysotypie adaptée. Les phages, virus isolés à partir de feuilles, de débris ou de sol prélevés dans des parcelles contaminées, ont une probabilité plus grande d'être en présence d'une souche agressive et donc d'être adaptés à ces souches. Afin de tester cette hypothèse, il serait intéressant d'essayer d'isoler des phages dans des régions où la bactérie est peu présente (zones forestières du Congo, par exemple) et de les mettre en présence des différentes souches de la collection.

Enfin, on a pu établir que les souches les plus agressives (et donc résistantes aux antibiotiques et sensibles aux phages) sont homogènes du point de vue de leur croissance sur différents substrats. Aucun mécanisme biologique ne semble pouvoir, à lui seul, expliquer le phénomène. En revanche, l'hypothèse d'une origine géographique commune plus ou moins éloignée dans le temps rend compte de cette conjonction. En outre, cette dernière hypothèse est cohérente avec l'absence de liaison entre le lieu d'isolement et le facteur commun de l'AFM. 
L'ensemble des considérations précédentes doit être rapproché du fait que les souches agressives, sensibles aux phages, résistantes aux antibiotiques sont peu variables du point de vue de l'ensemble de ces 3 critères comme du point de vue de la croissance sur différents substrats. Ceci suggère l'existence d'un ensemble homogène de souches sélectionnées et d'un ensemble hétérogène de souches sauvages. Une étude des relations sérologiques des souches permettrait de valider ou non cette hypothèse.

\section{RÉFÉRENCES}

Alves MLB, Takatsu A (1984) Variabilidade em Xanthomonas campestris pv manihotis. Fitopatol Bras $9,485-494$

Bauer AW, Kirby WMM, Sherris JC, Turck M (1966) Antibiotic susceptibility testing by a standardized single disk method, Am J Clin Pathol 45/41, 493493

Bradbury JF (1975) Bacterial diseases of Cassava, PANS 21, 44

Bradbury JF (1977) Xanthomonas manihotis, Descr pathog Fungi Bact, CMI Descr Pathog Fungi Bact, Kew, 559

Buruchara RA, Pastor-Corrales MA (1981) Variation, virulence of $P$ seudomonas syringae pv phaseolicola, In : Proc 5th int Conf Plant Pathog Bact, 16-23 august 1981, CIAT, Cali, Colombia, 341-351

Cuppels DA (1983) Isolation and characterization of phages useful for identifying Pseudomonas syringae pv Tomato, Phytopathology 73, 1376-1381

Daniel JF, Boher B, Kohler F (1981) Les maladies bactériennes du manioc (Manihot esculenta Crantz) en République populaire du Congo et en République Centrafricaine, Agronomie 1, 751-758

Elango F, Lozano JC (1981) Pathogenic variability of Xanthomonas manihotis the causal agent of cassava bacterial blight. Fitopatol Bras 6, 57-65

Elango F, Lozano JC, Person JF (198) Relationships between Xanthomonas campestris pv manihotis, Xanthomonas campestris pv cassavae and colombian yellowish isolates, 96-104. In : Proc 5th Int
Conf Plant Pathog Bact 16-23 august 1981, CIAT, Cali, Colombia

Endert E, Ritchie DF (1984) Detection of pathogenicity, measurement of virulence and determination of strain variation in Pseudomonas syringae pv syringae. Plant Dis 68, 677-680

Escoffier B, Pagès J (1988) Analyses factorielles simples et multiples. Objectifs, méthodes et interprétation. Dunod, Paris, $241 \mathrm{p}$

Ferron A (1974) Bactériologie à l'usage des étudiants en médecine. Grouau et Resques, Lille, $8^{\circ}$ éd

Grousson F (1986) Variabilité de Xanthomonas campestris pv manihotis. Thèse Docteur Ingénieur, INA, Paris, $142 p$

Hayward AC, Hogkiss W (1961) Taxonomic relationships of Xanthomonas uredovorus, J Gen Microbiol $26,133-140$

Lozano JC, Sequeira L (1974) Bacterial blight of cassava in Colombia : Etiology, Phytopathology 64, 7482

Manicom BQ, Becker MM, Deschodt C (1981) First report of cassava bacterial blight in South Africa, Phytophylactica 13, 195-196

Maraite M, Meyer JA (1975) Xanthomonas manihotis (Arthaud-Berthet) Starr, causal agent of bacterial wilt, blight and leaf spots of cassava in Zaîre, PANS $21,27-37$

Maraite M, Weyns J, Yinkwan O, Lipembra $P$, Perreaux D (1981) Physiological and pathogenic variations in Xanthomonas campestris pv manihotis. In : Proc 5th Int Conf Plant Pathog Bact 16-23 august 1981, CIAT, Cali, Colombia

Nair RR, Paily PV, Menon MR (1981) Symptomatology and etiology of bacterial blight of cassava (Manihot esculenta Crantz), Agric Res J Kerala, 19, 5962

Ride M (1963) Connaissances actuelles sur le chancre bactérien du peuplier dû à Aplanobacter populi, FAO/CIP

Robbs CF, Ribeiro $R$ De LD, Kimura O, Akiba F (1972) Variation in Xanthomonas manihotis (Arthaud-Berthet), Rev Soci Bras Fitopatol 5, 67-75

Stanier RY, Palleromi MJ, Doudoroff M (1966) The aerobic Pseudomonas: a taxonomic study, J Gen Microbiol 43, 159-271

Williams RJ, Agboola SD, Schneider RW (1973) Bacterial wilt of cassava in Nigeria, Plant Dis Rep 57, 824-827 